\title{
ANÁLISE DA APLICAÇÃO DA POLÍTICA NACIONAL DE RESÍDUOS SÓLIDOS NO MUNICÍPIO DE GURUPI - TO - LEI 12.305/2010
}

\section{ARTIGO ORIGINAL}

FILHO, Ademar Roberto Gross ${ }^{1}$

PICANÇO, Aurélio Pessôa ${ }^{2}$

FAGUNDES, Fabiano $^{3}$

SILVA, Julierme Siriano da ${ }^{4}$

RESENDE, Adriano de Oliveira ${ }^{5}$

FILHO, Ademar Roberto Gross. Et al. Análise da aplicação da Política Nacional de Resíduos Sólidos no Município de Gurupi - TO - Lei 12.305/2010. Revista Científica Multidisciplinar Núcleo do Conhecimento. Ano 05, Ed. 10, Vol. 02, pp. 7391. Outubro de 2020. ISSN: 2448-0959, Link de acesso: https://www.nucleodoconhecimento.com.br/engenharia-civil/analise-daaplicacao

\footnotetext{
${ }^{1}$ Graduando em Engenharia Civil.

2 Orientador. Doutorado em Hidráulica e Saneamento. Mestrado em Hidráulica e Saneamento. Graduação em andamento em Direito. Graduação em Engenharia Sanitária.

${ }^{3}$ Mestrado em andamento em Engenharia Ambiental. Especialização em Engenharia De Segurança Do Trabalho. Graduação em Engenharia Civil.

4 Mestrado profissional em Mestrado Profissional em Engenharia Ambiental. Especialização em Gestão Pública com Ênfase em Desenvolvimento de Projetos. Graduação em Engenharia Civil.

${ }^{5}$ Especialização em Direito Processual Civil. Graduação em Direito.
} 


\section{RESUMO}

A Lei 12.305, de 02 de agosto de 2010 que instituiu a Política Nacional de Resíduos Sólidos estabeleceu novas diretrizes aos municípios brasileiros quanto à destinação final adequada destes materiais, no entanto, os gestores municipais veem enfrentando grandes dificuldades para o atendimento à Lei, pois a mesma é ampla, complexa, com vários fatores envolvidos, requerendo o empenho de altos valores para implantação e operação. Partindo deste contexto, o objetivo deste artigo foi analisar a aplicação das políticas públicas implantadas pelo Governo Municipal para o atendimento da Política Nacional de resíduos Sólidos no Município de Gurupi, Tocantins. Constata-se que a coleta de resíduos sólidos no município tem boa funcionalidade e a gestão municipal busca melhorias para aperfeiçoar o processo, porém esbarra no quesito financeiro. Quanto ao Aterro Sanitário de Gurupi, o mesmo possui deficiências na operacionalidade e dificuldades de atendimento à totalidade das demandas da Lei 12.305/2010, em contrapartida é bem conceituado pela Fundação Nacional da Saúde, demonstrando-se ser referência no estado. Dessa forma o presente artigo apresenta o diagnóstico da situação atual operacional dos resíduos sólidos no município de Gurupi.

Palavras-chave: resíduos sólidos, aterro sanitário, limpeza urbana.

\section{INTRODUÇÃO}

A política ambiental brasileira vem sendo debatida desde meados do século XX e com a promulgação da Constituição de 1988 a temática se tornou constante até que em $1^{\circ}$ de abril de 1991 o Projeto de Lei sobre Resíduos Sólidos (RU) foi apresentado à Câmara dos Deputados. No transcorrer de quase vinte anos de tramitação, passando por avaliações e ajustes, acabou sendo aprovada em agosto do ano de 2010 a Lei 12.305 - Política Nacional de Resíduos Sólidos - PNRS que, entre outros, dispõe sobre a não geração, redução, reutilização e tratamento de resíduos sólidos, bem como destinação final ambientalmente adequada dos rejeitos. 
A partir da entrada em vigor da Lei no 12.305/2010, sob a coordenação do Ministério do meio Ambiente, os municípios brasileiros buscam se adaptar a essas novas exigências e atender as diretrizes normativas do Plano Nacional de Resíduos Sólidos, tendo como contraponto, muitas vezes, o impacto orçamentário na maioria das prefeituras por todo o País. Segundo a Lei 12.305, para a implantação, tanto para o Plano Nacional de Resíduos Sólidos quanto para o Plano Estadual de Resíduos Sólidos, estabeleceu-se prazos de vigência indeterminado e horizonte de 20 (vinte) anos, com proposta de atualização a cada 4 (quatro anos) com seus respectivos incisos.

O gerenciamento de resíduos sólidos constantes nos planos nacional e estadual contempla diversas etapas dentre elas: coleta, transporte, transbordo, tratamento, destinação final dos resíduos e disposição final ambientalmente adequada dos rejeitos (BRASIL, 2010). Tal aplicabilidade depende muitas vezes das condições econômicas do município, dificultando o atendimento à Lei no prazo pré-estabelecido. Segundo o Jornal do Tocantins em matéria publicada por Luana Fernanda em 05/09/18, apenas três cidades do Tocantins possuem aterros sanitários, são elas: Palmas, Araguaína e Gurupi, já os municípios de Brejinho de Nazaré, Santa Rosa, Colinas do Tocantins, Itacajá, Itupiratins, Lavandeira e Dois Irmãos têm aterros controlados. Os demais 129 municípios descartam os resíduos sólidos de forma irregular em "Lixões" a céu aberto.

A realização deste trabalho justifica-se em função da necessidade do conhecimento de informações à cerca do futuro sustentável da região sul do Tocantins e da qualidade de vida de sua população futura, como também, sobre mudanças de comportamentos que as exigências da PNRS estabeleceram ao mercado, à sociedade e ao poder público. Neste contexto, este trabalho de estudo de caso, visa a observância da aplicabilidade da Lei 12.305/2010 no município de Gurupi -TO por meio do PLANO MUNICIPAL DE GESTÃO INTEGRADA DE RESÍDUOS SÓLIDOS DE GURUPI-TO (PMGIRS) de agosto de 2013, relacionando os serviços prestados e os esforços do poder público quanto ao atendimento da PNRS no que tange aos desafios de promover padrões mais sustentáveis de produção e consumo sem comprometer a qualidade ambiental. (PMGIRS, 2013) 


\section{REVISÃO DE LITERATURA}

A NBR 10.004 de 2004 define Residuos Sólidos (RU) como:

Resíduos nos estados sólido e semi-sólido, que resultam de atividades da comunidade de origem: industrial, doméstica, hospitalar, comercial, agrícola, de serviços e de varrição. Ficam incluídos nesta definição os lodos provenientes de sistemas de tratamento de água, aqueles gerados em equipamentos e instalações de controle de poluição.(ABNT, 2004).

A Lei Federal no 12.305/2010, define em seu artigo 3o que os resíduos sólidos são:

Material, substância, objeto ou bem descartado resultante de atividades humanas em sociedade, a cuja destinação final se procede, se propõe proceder ou se está obrigado a proceder, nos estados sólido ou semissólido, bem como gases contidos em recipientes e líquidos cujas particularidades tornem inviável o seu lançamento na rede pública de esgotos ou em corpos d'água, ou exijam para isso soluções técnicas ou economicamente inviáveis em face da melhor tecnologia disponível (BRASIL, 2010, p. 2).

A Política Nacional de Resíduos Sólidos - PNRS descreve Resíduos Sólidos Urbanos (RSU) com sendo os resíduos de origem domiciliar, de atividades domésticas em residências urbanas, de limpeza urbana originários de varrição, limpeza de logradouros e vias públicas, e demais serviços de limpeza urbana. Ainda, a lei diferencia o termo "rejeito" como aquele resíduo para o qual não há possibilidades de tratamento e recuperação por processos tecnológicos disponíveis economicamente viáveis, tendo somente a disposição final ambientalmente adequada como única possibilidade (BRASIL, 2010).

De acordo com a Associação Brasileira de Empresas de Limpeza Pública e Resíduos Especiais - ABRELPE no ano de 2015, no Brasil, foi produzido cerca de 79,9 milhões de toneladas de RSU. Deste total, 90,8\% passou pelo processo de coleta. Entretanto, o problema desse sistema está na disposição final, pois, do montante coletado, apenas $58,7 \%$ foram destinados adequadamente para os aterros sanitários.

O Sistema Nacional de Informações sobre Saneamento (SNIS) em seus relatorios do ano de 2014, descreve que há um total de 64,4 milhões de toneladas coletadas de 
resíduos domiciliares por ano nos municípios brasileiros, o que equivale a aproximadamente 176,4 mil toneladas por dia. (BRASIL, 2016).

O SNIS cita também que os aterros sanitários continuam sendo a tecnologia mais aplicada para a disposição de RSU. (BRASIL, 2016).

Conforme consta no Capítulo II, Seção IV Art. 18 da Lei 12305 e 2010:

A confecção e implementação dos Planos Municipais de Gestão Integrada de Resíduos Sólidos, são requisitos para os municípios terem acessos a recursos da União, ou por ela controlados, destinados a empreendimentos e serviços relacionados à limpeza urbana e ao manejo de resíduos sólidos, ou para serem beneficiados por incentivos ou financiamentos de entidades federais de crédito ou fomento para tal finalidade, (BRASIL, 2010).

No $\S 2^{\circ}$ do Art. 19 da Lei 12.305 de 2010 cita que "para Municípios com menos de 20.000 (vinte mil) habitantes, o plano municipal de gestão integrada de resíduos sólidos terá conteúdo simplificado, na forma do regulamento". (BRASIL, 2010).

Na Seção V da LEI 12.305/2010 é estabelecida a obrigatoriedade da criação do Plano de Gerenciamento de Resíduos Sólidos para os geradores de resíduos sólidos, tendo suas respectivas definições de acordo com o art. 13 da respectiva lei:

a) Resíduos domiciliares: os originários de atividades domésticas em residências urbanas; b) Resíduos de limpeza urbana: os originários da varrição, limpeza de logradouros e vias públicas e outros serviços de limpeza urbana; c) Resíduos de estabelecimentos comerciais e prestadores de serviços: os gerados nessas atividades; d) Resíduos dos serviços públicos de saneamento básico: os gerados nessas atividades; e) Resíduos industriais: os gerados nos processos produtivos e instalações industriais; f) Resíduos de serviços de saúde: os gerados nos serviços de saúde, conforme definido em regulamento ou em normas estabelecidas pelos órgãos do Sisnama; g) Resíduos da construção civil: os gerados nas construções, reformas, reparos e demolições de obras de construção civil, incluídos os resultantes da preparação e escavação de terrenos para obras civis; h) Resíduos agrossilvopastoris: os gerados nas atividades agropecuárias e silviculturais, incluídos os relacionados a insumos utilizados nessas atividades; i) Resíduos de serviços de transportes: os originários de portos, aeroportos, terminais alfandegários, rodoviários e ferroviários e passagens de fronteira; j) Resíduos de mineração: os gerados na 
atividade de pesquisa, extração ou beneficiamento de minérios (BRASIL, 2010).

Ainda em conformidade com a Lei 12.305/2010, no artigo terceiro temos descrito que "o poder público, o setor empresarial e a coletividade são responsáveis pela efetividade das ações voltadas para assegurar a observância da Política Nacional de Resíduos Sólidos e das diretrizes e demais determinações estabelecidas." (BRASIL, 2010), em seu Art. 23 estabelece que:

Os responsáveis pelo Plano de Gerenciamento de Resíduos Sólidos manterão atualizadas e disponíveis ao órgão municipal competente, ao órgão licenciador do Sistema Nacional do Meio Ambiente (Sisnama) e a outras autoridades, informações completas sobre a implementação e a operacionalização do plano sob sua responsabilidade. (BRASIL, 2010).

Mersoni apud Lima (2000) cita que:

O gerenciamento de resíduos sólidos é pautado nos aspectos tecnológicos e operacionais, envolvendo fatores administrativos, gerenciais, econômicos, ambientais, de desempenho (produtividade e qualidade), incluindo prevenção, redução, segregação, reutilização, acondicionamento, coleta, transporte, tratamento, recuperação de energia e destinação final.

O município de Gurupi - TO, investigado neste trabalho está localizada na região sul do Tocantins, às margens da BR-153 (Rodovia Belém-Brasília) a 223 km de Palmas, capital do Estado, conforme consta na Figura 1. Gurupi possui aproximadamente 85.737 habitantes, sua sede localiza-se a latitude $11^{\circ} 43^{\prime} 48^{\prime \prime}$ sul e longitude $49^{\circ} 04^{\prime} 08^{\prime \prime}$ oeste, estando a uma altitude de 287 metros (IBGE, 2018). 
Figura 1- Localização da área de estudo.

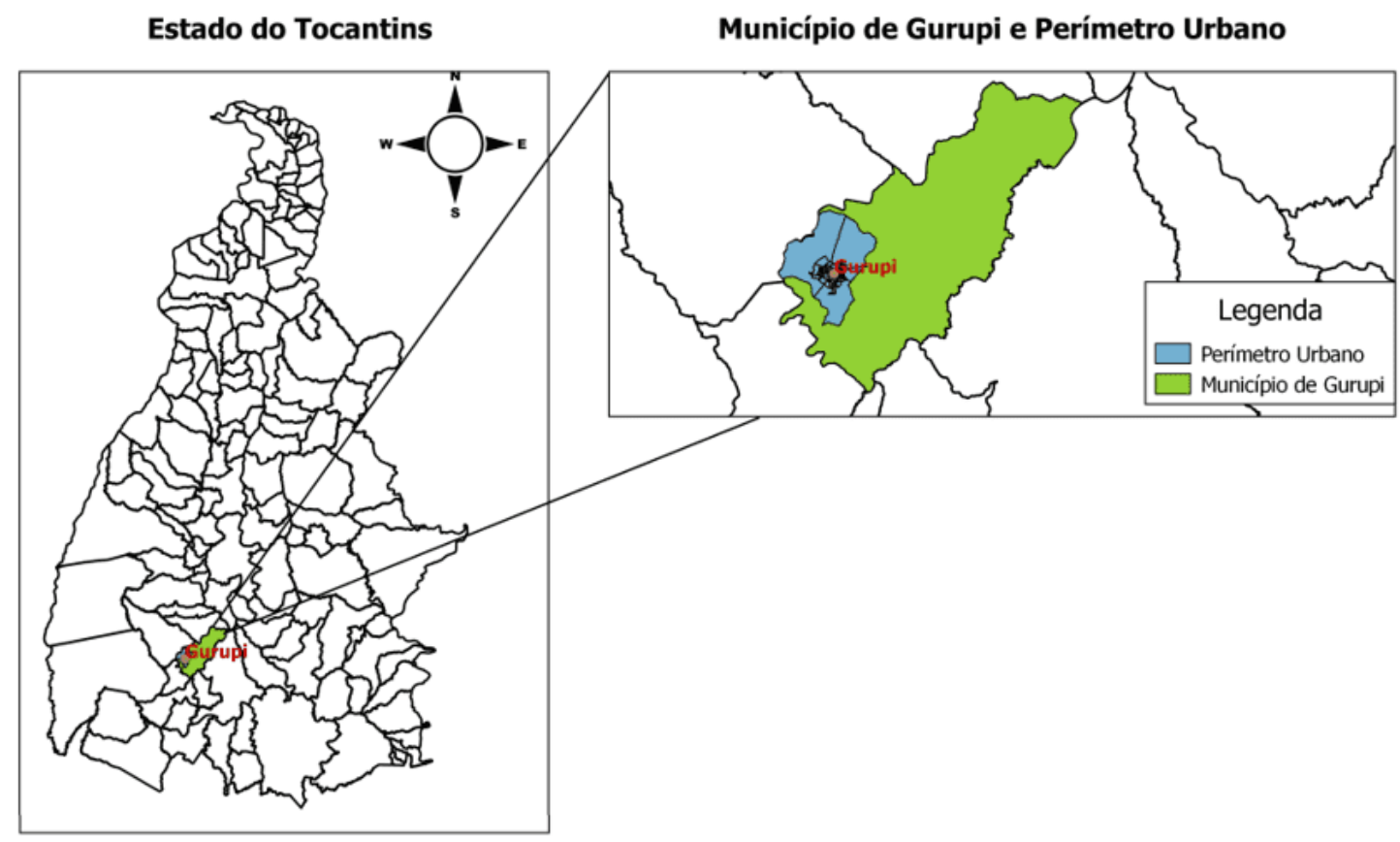

Fonte: Autor, 2018.

A Região Sul do Tocantins tem como referência a Região Metropolitana de Gurupi instituída pela Lei Estadual Complementar № 93, de 3 de abril de 2014, constituída por 18 municípios: Aliança do Tocantins; Alvorada; Araguaçu; Cariri do Tocantins; Crixás do Toducantins; Dueré; Figueirópolis; Formoso do Araguaia; Gurupi; Jaú do Tocantins; Palmeirópolis; Paranã; Peixe; Sandolândia; São Salvador do Tocantins; São Valério da Natividade; Sucupira; Talismã. De acordo com o Censo IBGE de 2010, do total da população do município de Gurupi, 97,7\% mora na cidade e 2,3\% são moradores da zona rural, 49,7\% são do sexo masculino e 50,4\% são do sexo feminino. Tal como citado, Gurupi é polo regional e possui potencial para sediar um aterro sanitário de grande capacidade num possível consórcio entre os demais municípios (SECRETARIA DE INFRAESTRUTURA DE GURUPI, 2018).

\section{METODOLOGIA}

Este trabalho trata-se de uma pesquisa de ordem qualitativa de forma indutiva não havendo a necessidade de técnicas ou métodos estatísticos, conforme descreve Gil 
(2006). Aplica-se a este estudo, conhecimento teórico por meio de literatura pertinente, como legislação vigente, dados em sites de organizações e institutos, assim como pesquisa aplicada aos gestores envolvidos na aplicação do Plano Municipal de Gestão Integrada de Resíduos Sólidos de Gurupi - TO, 2013.

Foi utilizado o estudo de caso, pois sua utilização tecnica, de acordo com GIL (2006) busca "descrever a situação do contexto em que está sendo feita determinada investigação"

Para a coleta de dados foram realizadas entrevistas com o secretário municipal de infraestrutura, com a Secretaria de Produção, Cooperativismo e Meio Ambiente (SPCMA), assim como também, o envio por e-mail de questionário contendo questões simples e diretas ao departamento de planejamento de limpeza e coleta de resíduos do município. Houve ainda, visitas no aterro sanitário de Gurupi, no galpão da Associação Gurupiense de Catadores e Catadoras de Materiais Recicláveis, no depósito de pneus inservíveis do município e no depósito de resíduos da construção civil.

\section{RESULTADOS E DISCUSSÃO}

\subsection{GESTÃO E COLETA DOS RESÍDUOS SÓLIDOS}

O secretário municipal de infraestrutura, investido no cargo desde 02 de janeiro de 2013, é responsável pela execução do Plano Municipal de Gestão Integrada de Resíduos Sólido de Gurupi - TO e de acordo com suas informações o Município de Gurupi tem por base uma produção de $900 \mathrm{~g}$ dia $^{-1}$ de resíduo doméstico per capta, com custo operacional total mensal de aproximadamente $\mathrm{R} \$ 350.000,00$ (trezentos e cinquenta mil reais). Aponta que a última proposta para terceirização do serviço de coleta, a empresa interessada propôs o valor mensal de aproximado de $\mathrm{R} \$$ $800.000,00$ (oitocentos mil reais). Destacou que a coleta no setor central da cidade e nos lugares de maior concentração comercial é diferente dos demais bairros. No centro a coleta é realizada por conteinerização diariamente, já nos bairros periféricos a coleta é realizada ponto a ponto, três vezes por semana, sendo trabalhada nos três 
turnos (Matutino; Vespertino e Noturno), em todos os casos com caminhão compactador com capacidade para 8 (oito) toneladas, tendo abertura traseira. A coleta por contêiner foi um experimento bem sucedido, segundo seus relatos, com 200 unidades iniciais e aguarda a chegada de mais 500 contêineres que se encontra em processo licitatório para aquisição, pretendendo futuramente atingir na totalidade, a coleta por quadra (contêiner). A Secretaria de Infraestrutura do município informa ainda, que a meta da gestão municipal é implantar a coleta seletiva até o ano de 2020, porém ainda não possui um planejamento orçamentário específico para isso.

A frota veicular de Gurupi disponível para a coleta, transporte e compactação, conforme descrito na Tabela 1, conta com 22 motoristas e 48 auxiliares para operacionalização.

Tabela 1- Veículos utilizados para coleta, transporte e compactação de resíduos sólidos.

\begin{tabular}{|l|l|l|}
\hline Equipamento / RH & Quantidade & Especificação \\
\hline Caminhão Compactador (8T) & 5 & Câmbio automático \\
\hline Caminhão Compactador - Reserva (8T) & 2 & Câmbio manual \\
\hline Caminhão Truck - Caçamba & 3 & Basculante \\
\hline Caminhão Truck - Caçamba & 1 & - \\
\hline Escavadeira Hidráulica & 1 & - \\
\hline Trator de Esteira & 1 & - \\
\hline Total & 13 & - \\
\hline
\end{tabular}

Fonte: Secretaria de Infraestrutura de Gurupi (2018).

A Secretaria Municipal de Infraestrutura trabalha em conjunto com a Secretaria de Produção, Cooperativismo e Meio Ambiente (citado a partir daqui como Secretaria de Meio Ambiente) no que tange à PNRS, atuando conjuntamente no planejamento, execução, fiscalização e em procedimentos burocráticos. 


\subsubsection{RESÍDUOS SÓLIDOS URBANOS}

Segundo a PNRS "são os resíduos domiciliares originários de atividades domésticas em residências urbanas e os resíduos de limpeza urbana: os originários da varrição, limpeza de logradouros e vias públicas e outros serviços de limpeza urbana" (BRASIL, 2010).

\subsubsection{RESÍDUOS DOMICILIARES}

São coletados diariamente 90 toneladas de resíduos domiciliares em toda a zona urbana de Gurupi - TO. A forma como é feita a coleta e disposição final do resíduo doméstico de Gurupi, segundo a Coordenação de Limpeza Urbana, é manual/mecanizada (caminhão coletor). O Resíduo Sólido Doméstico (RSD) é coletado por uma equipe de 22 motoristas e 48 servidores, todos com seus respectivos EPIs, cada caminhão coletor possui o recurso de compactação do resíduo doméstico, acionado manualmente, quando 0 volume na parte traseira impede 0 acondicionamento de novas sacolas de resíduos. Quando toda a capacidade de acondicionamento é preenchida, o veículo é conduzido para descarte organizado no Aterro Sanitário de Gurupi. A coleta e o transporte dos RSD, exceto os provenientes da varrição manual, realizam-se com guarnição composta de no mínimo um motorista e um coletor por veículo coletor que esteja empregado na atividade. O serviço é contínuo nos três turnos (matutino, vespertino e noturno) de segunda-feira à sábado, inclusive nos feriados. Os materiais cortantes e perfurantes, na sua maioria vidros de para-brisas de veículos, estão sendo recebidos diretamente no aterro sanitário e dispostos em valas próprias para esse fim (SECRETARIA DE INFRAESTRUTURA DE GURUPI, 2018; PMGIRS, 2013).

\subsubsection{RESÍDUOS DE LIMPEZA URBANA}

De acordo com a Coordenação de Limpeza Urbana, para a coleta de resíduos de limpeza urbana, nos logradouros públicos, o município tem à disposição 85 servidores que utilizam como equipamento: vassourão, carrinho de mão de coleta, pás e EPIs. Para este serviço de varrição, são gastos mensalmente os valores aproximados de 
$R \$ 140.000,00$. Gurupi ainda não conta com serviço de varrição mecanizada, porém uma das propostas da atual gestão é a aquisição deste equipamento. Nas feiras municipais, tanto nas fixas como móveis, tem-se o planejamento para coleta do RSU conforme calendário semanal dos eventos.

Em relação à roçagem e capina, são 30 servidores atuantes que têm à disposição trator equipado com hélice de corte, além de roçadeiras portáteis à gasolina. $\mathrm{O}$ trabalho é praticado durante o período de chuvas e abrange toda a região urbana de Gurupi (SECRETARIA MUNICIPAL DE INFRAESTRUTURA DE GURUPI, 2018).

Ainda segundo a Coordenação de Limpeza Urbana, existe um plano municipal de manutenção e podas. Para os serviços de pintura de meio-fio e praças do município, são utilizados 12 servidores que contam com um caminhão trucado e um caminhão de apoio, a pintura é realizada com a cal, abrangendo somente a parte urbana do município. Esta mesma equipe trabalha durante todo o ano na retirada e transporte de galhadas, tendo à disposição caminhão de apoio e caminhão basculante para transporte destes resíduos. Os resíduos vegetais também são dispostos no aterro sanitário por veículos particulares. Não havendo a trituração para compostagem e ou queima em fornos, somente uma compactação por trator esteira em vala própria.

\subsubsection{RESÍDUOS DE SERVIÇOS DE SAÚDE}

De acordo com a Coordenação de Limpeza Urbana, quanto à destinação dos Resíduos Sólidos da Saúde, o Município mantém um contrato, por meio de licitação, com a empresa Indcom Ambiental, especializada neste segmento que faz a coleta e disposição final. São gastos mensalmente $R \$ 10.000,00$ no contrato por um volume de $1500 \mathrm{~kg}$ mensal, como também, a disponibilização de dois servidores para a coleta (SECRETARIA MUNICIPAL DE INFRAESTRUTURA DE GURUPI, 2018). 


\subsubsection{RESÍDUOS DOS SERVIÇOS PÚBLICOS DE SANEAMENTO BÁsICO}

O lodo proveniente das Estações de Tratamento de Água e Esgoto do município gerenciado pela empresa BRK não é destinado ao aterro sanitário municipal, ficando deste modo, ainda sob responsabilidade de estocagem por parte da empresa, em bags, até que se comprove ser atóxico. Porém há espaço planejado no aterro sanitário para receber tal produto em vala especialmente dimensionada (SECRETARIA DE PRODUÇÃO, COOPERATIVISMO E MEIO AMBIENTE, 2018).

\subsubsection{RESÍDUOS DA CONSTRUÇÃO CIVIL}

A Resuolução CONAMA no 307, de 5 de julho de 2002 define resíduos da Construção Civil como:

Os resíduos provenientes de construções, reformas, reparos e demolições de obras da construção civil, e os resultantes da preparações e da escavação de terrenos, tais como, tijolos, blocos cerâmicos, concreto em geral, solos, rochas, metais, resinas, colas, tintas, madeiras e compensados, forros, argamassas, gesso, telhas, pavimento asfáltico, vidros, plásticos, tubulações, fiação elétrica, entre outros, comumente chamados de entulhos de obras. (BRASIL, 2002)

Os resíduos da construção civil podem ser dispostos em áreas degradadas, através de Plano de Recuperação de Áreas Degradadas (PRADE), segundo o Plano Municipal de Gestão Integrada de Resíduos Sólidos - PMGIRS (2013). Em Gurupi a área designada pelo município está localizada próximo à Rodovia BR 163, vizinho ao posto de combustível Décio, há $12 \mathrm{~km}$ da sede do município. A coleta e transporte são realizados por caminhão basculante da prefeitura e empresas locais de locação de contêineres para este tipo de RS. Não é possível mensurar o volume mensal, visto que, é totalmente variável em função do setor econômico da construção civil (SECRETARIA DE PRODUÇÃO, COOPERATIVISMO E MEIO AMBIENTE, 2018). 


\subsubsection{RESÍDUOS INDUSTRIAIS}

A Secretaria de Meio Ambiente cita que no município a geração, coleta e destinação final dos resíduos industriais são de única exclusividade dos próprios geradores, não cabendo à prefeitura o descarte dos mesmos, exceto quando dispostos irregularmente nas ruas e logradouros, sem a possibilidade de identificação dos responsáveis.

\subsubsection{COLETA SELETIVA}

De acordo com a Secretaria de Meio Ambiente, por enquanto, a única coleta seletiva ocorre em parte dos resíduos sólidos do setor central (comercial), por parte da Associação Gurupiense de Catadores e Catadoras de Materiais Recicláveis (AGCCMR) que estão sediados no Setor Industrial do Município, em galpão cedido pelo município utilizando-se de um caminhão truck, também cedido pela prefeitura, juntamente com um motorista. Os cinco catadores catalogados, segundo a FUNASA (2018), têm a disposição neste depósito duas prensas para compactação dos resíduos selecionados, sendo uma, cedida pela DEIC - Delegacia Especializada em Investigações Criminais do estado do Tocantins. Todo o material selecionado pelos associados é vendido e o valor é totalmente revertido para a AGCCMR sem interferência do município.

\subsubsection{RESÍDUOS SÓLIDOS ESPECIAIS}

Os resíduos sólidos como pilhas e lâmpadas fluorescentes não tem programação de coleta especial para logística reversa, deste modo é descartado no Aterro Sanitário de Gurupi misturados aos demais RSU.

Quanto aos pneus, em atendimento à Resolução CONAMA № 258 de 1999, alterada pela Resolução № 301 de 2003 em seus artigos 1ํㅜ e 9o, não serão recebidos em Aterro Sanitário ou célula sanitária, sendo encaminhados para o ecoponto de pneus existente no Parque Agroindustrial de Gurupi, para posterior encaminhamento para a correta destinação e disposição finais através de parceria já estabelecida, responsável para dar a destinação e disposição final ambientalmente adequada aos pneus inservíveis através de sistema de logística reversa (PMGIRS, 2013). 
Segundo dados da Secretaria de Meio Ambiente e posterior visita de averiguação, o município de Gurupi conta com um galpão no setor industrial para estocagem de pneus inservíveis, que ao ter esgotada sua capacidade de armazenamento, tem por procedimento, o transporte para indústrias que utilizam este material como combustível. É importante salientar que no município existem empresas revendedoras de pneus, porém não praticam a logística reversa, deixado desta forma, a cargo da gestão municipal essa incumbência.

\title{
5.2 ATERRO SANITÁRIO
}

De acordo com o Plano Municipal de Gestão Integrada de Resíduos Sólidos (2013):

\begin{abstract}
Aterro Sanitário: é um espaço destinado à deposição final de resíduos sólidos gerados pela atividade humana. Nele são dispostos resíduos domésticos, comerciais, de serviços de saúde, da indústria de construção, e também resíduos sólidos retirados do esgoto. A base do aterro sanitário deve ser constituída por um sistema de drenagem de efluentes líquidos percolados (chorume) acima de uma camada impermeável, evitando assim a contaminação de lençóis freáticos. O chorume deve ser tratado e/ou recirculado (reinserido ao aterro) causando assim uma menor poluição ao meio ambiente. Deve possuir, também, um sistema de coleta e aproveitamento dos gases, sistema de drenagem superficial e sistema de monitoramento ambiental.
\end{abstract}

Deste modo, é possível conceituar a destinação final dos resíduos sólidos do município de Gurupi como Aterro Sanitário.

O Aterro Sanitário do municipio de Gurupi está localizado no Lote nำ12-F do Loteamento Fazenda Santo Antônio, Gleba 8, 4를 Etapa, Gurupi - TO, e em área anexa ao antigo Aterro Controlado, e "não se encontra em área de proteção ambiental e nem com restrição urbana. $O$ mesmo foi implantado em conformidade com as condicionantes estabelecidas na LO n 262/2006 e com todas as exigências e recomendações estabelecida pelo NATURATINS" (PMGIRS, 2013).

De acordo com o Plano Municipal de Gestão Integrada de Resíduos Sólidos (PMGIRS) de Gurupi-TO: 
A área do antigo aterro controlado de Gurupi encontra-se hoje reflorestada com vegetação nativa de cerrado. Constantemente são executadas inspeções visuais periódicas de prevenção de fogo, e para a identificação e o acompanhamento de possíveis recalques diferenciais e totais decorrentes da estabilização da matéria orgânica e das poropressões de gases e de efluentes líquidos no interior da massa de resíduos ou até por alterações provocadas por chuvas. (PMGIRS, 2013).

O aterro atualmente possui quatro piezômetros para análise da qualidade da água, com ensaios realizados duas vezes ao ano, inclusive monitora a qualidade das águas do córrego Mato do Gado (FUNASA, 2018). Para operacionalização atualmente conta 20 operários e equipamentos como uma escavadeira hidráulica, um trator de esteiras e três caminhões com caçamba basculante. Possui plano de execução de aceiros para prevenção de incêndios. Nas valas antigas (inativas) de deposição são indicados os lotes com suas respectivas datas de abertura e finalização (SECRETARIA DE INFRAESTRUTURA DE GURUPI, 2018).

A Secretaria de Infraestrutura de Gurupi informa que o aterro sanitário recebe diariamente em média 80 toneladas de resíduos sólidos, perfazendo um total anual de 28.800 toneladas, estes volumes de resíduos geram cerca de 37.900 litros por ano de chorume. A drenagem deste chorume é feita através de valas, tendo em seu interior tubo de PVC de $100 \mathrm{~mm}$ furado, como também manilhas perfuradas de concreto que são fabricadas no próprio aterro sanitário, sendo os mesmos envoltos com Pedra de Mão. Esse chorume se interliga em várias caixas de passagem (CP) com destino final em duas lagoas de chorume totalmente impermeabilizadas com geomembrana, onde naturalmente se evapora.

Todo o RSU gerado "tem descarga dentro da vala, na frente de operação, espalhamento e compactação diária com trator de esteira, em camadas de espessura uniforme, com inclinação superficial mínima de $2 \%$ em direção aos bordos da camada" (PMGIRS, 2013), a periodicidade de recobrimento com camada de argila dos resíduos sólidos compactados é semanal com espessura de no mínimo $10 \mathrm{~cm}$ (camada intermediária) sendo que a altura entre as camadas intermediárias será de $0,5 \mathrm{~m}$ a 1,0 m. De acordo com a Secretaria de Meio Ambiente, o aterro não conta com o aproveitamento dos gases gerados, visto que, após estudos de viabilidade, não se 
apresentou interessante do ponto de vista econômico. A maior vala do aterro sanitário está em operação há três anos, atualmente está próximo da sua capacidade total, com isso já existe a abertura de uma nova vala de grandes dimensões conforme figura 2, a geomembrana que impermeabilizará sua parte inferior em contato com o solo natural está em processo de entrega por parte do fornecedor.

Figura 2- Imagem aérea de nova vala e lagoas de chorume do aterro sanitário de Gurupi.

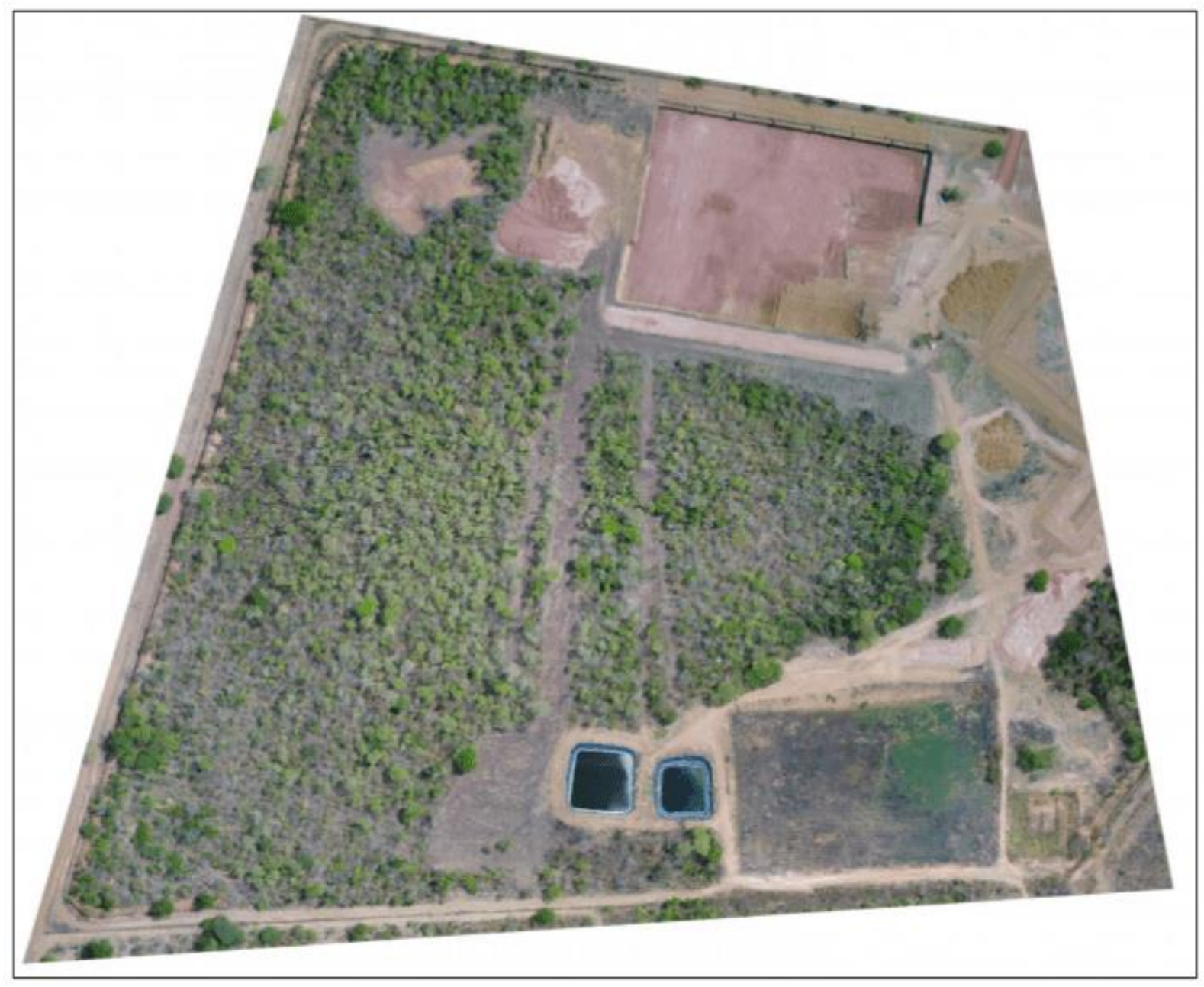

Fonte: Secretaria de Infraestrutura de Gurupi, 2018.

A projeção feita sobre a vida útil do Aterro Sanitário de Gurupi indicou que se mantendo a operação de destinação e disposição final atual como referência, a 
capacidade operacional será até o ano de 2043, não se descartando a possibilidade de sua capacidade se estender até 2053.

Pode ser observado que mesmo tendo, em outra localidade, o aterro próprio de resíduos sólidos de construção, o Aterro Sanitário de Gurupi recebe uma pequena parte deste tipo de resíduo sólido. Também se observou a presença de resíduos volumosos como colchões e sofás, além de monitores de TV, CPUs e impressoras que estão sendo empilhados sobre a área das valas do antigo lixão. Estes resíduos de equipamentos eletroeletrônicos que contêm sódio, mercúrio, ferro, cobre, vidro, cerâmica, chumbo, sílica, arsênico, cromo hexavalente, retardantes de chama bromados e halogenados, clorofluorcarboneto, bifenilas policloradas e cloreto de polivinila são considerados como resíduos Classe I segundo a Lei 12.305/2010, portanto seus descarte neste local se torna inadequado.

É importante salientar que a prefeitura faz o recolhimento de carcaças de animais encontrados em logradouros, estas são levadas para o aterro sanitário de Gurupi que possui vala apropriada para este tipo de resíduo.

Em relação aos resíduos de drenagem, Gurupi possui uma malha pequena, apenas central, produzindo pouquíssimo resíduo desse tipo, praticamente coletado junto aos resíduos de varrição (SECRETARIA DE INFRAESTRUTURA DE GURUPI, 2018).

Em visita técnica ao aterro sanitário de Gurupi, pode-se constatar que todo o seu perímetro é cercado, existe uma guarita na entrada para controle de acesso e contagem dos caminhões que entram para despejo dos RSU com dois funcionários constantemente. Observou-se que não havia a presença de catadores e animais nas dependências do aterro, exceto urubus. O funcionamento do aterro é de 8:00 horas às 11:30 horas e de 13:00 horas às 17:00 horas todos os dias, inclusive domingos e feriados.

Segundo informações da Coordenação de Limpeza Urbana, entram diariamente no aterro sanitário: 10 caminhões coletores com capacidade para 8 toneladas, sendo: 5 caminhões pela manhã, 2 caminhões à tarde e 3 caminhões à noite, assim como, 
aproximadamente 6 caminhões caçamba com galhadas (SECRETARIA DE INFRAESTRUTURA DE GURUPI, 2018).

O custo operacional do Aterro Sanitário de Gurupi, segundo dados da FUNASA (2018), é de $R \$ 130.000,00$ por mês.

Desde 2006 quando foi criado o Lixão, passando a Aterro Controlado e instituído o Aterro Sanitário de Gurupi a temática da PNRS vem sendo tratada com seriedade pela gestão municipal, tanto que de acordo com o Ofício Circular no 2/DIESP-TO de 03 de julho de 2018 da Fundação Nacional de Saúde - FUNASA a situação do aterro sanitário é considerada como "Operação Adequada" com Índice de Qualidade de Resíduo - IQR $=8,1$, sendo que, a conceituação de 0,0 a 7,0 é classificada como "Condições Inadequadas" e de 7,1 a 10,0 como "Condições Adequadas".

De acordo com a FUNASA (2018), está em discussão na Assessoria Jurídica do Município, a criação de Consórcio Público com cerca de cinco municípios para a gestão dos resíduos sólidos. São objetos do convênio: a) Serviços preliminares; b) Sistema de tratamento de chorume (Lagoas: Anaeróbia, facultativa e maturação); c) Sistema de gases e percolados; d) Sistema de drenagem; e) Rede coletora de chorume; f) Estrutura de apoio; g) Galpão para máquinas; h) Guarita; i) Construção de cerca de arame, esta proposta poderia implicar em ganho de qualidade, não só para Gurupi, que teria uma capacidade tecnológica superior de operacionalização, como também para os demais municípios participantes deste consórcio, visto que estes atenderiam o tratamento de seus RSU de forma ambientalmente adequada.

\section{CONSIDERAÇÕES FINAIS}

De acordo com a Secretaria de Infraestrutura, o município de Gurupi ainda não atende na totalidade a Lei 12.305 de 2010 que institui a PNRS, porém cita que houve muitos esforços para chegar ao patamar em que está atualmente e que dentre os demais municípios do estado do Tocantins, avaliados pela FUNASA, Gurupi se encontra como o terceiro mais eficiente. 
Contudo, o Aterro Sanitário de Gurupi não conta com informações da composição gravimétrica dos resíduos sólidos urbanos domiciliares, como também, deixa de atender a várias diretrizes da Lei 12.305/2010, ou seja, está longe de atender qualitativamente a referida Lei.

Quanto ao Município de Gurupi, cabe a revisão de seu Plano Municipal de Gestão Integrada de Resíduos Sólidos (PMGIRS), no máximo a cada 05 (cinco) anos, que deverá ser elaborado de acordo com a legislação em vigor, em especial às Leis Federais № 11.445/ 2007 e 12.305/2010, além de atender às particularidades locais do Município, porém com a formação do Conselho Municipal de Saneamento Básico somente em 2017, estas pautas estão pendentes, visto que o PMGIRS foi criado em 2013, porém percebe-se boa vontade naqueles que ali estão, pois o Conselho atua de forma voluntária.

A avaliação das ações desenvolvidas e os resultados alcançados permitem compreender as potencialidades da Lei 12.305/2010, e seu forte caráter de intervenção no planejamento das políticas públicas governamentais. É importante ressaltar que o trabalho conjunto de todas as esferas da sociedade são indispensáveis para a totalidade da realização da Política Nacional de Resíduos Sólidos.

\section{REFERÊNCIAS}

ASSOCIAÇÃO BRASILEIRA DE EMPRESAS DE LIMPEZA PÚBLICA E RESÍDUOS ESPECIAIS (ABRELPE). Panorama de Resíduos Sólidos no Brasil. ABRELPE, 2015.

ASSOCIAÇÃO BRASILEIRA DE NORMAS TÉCNICAS (ABNT) NBR 10.004. Resíduos sólidos-Classificação. Rio de Janeiro, 2004.

BRASIL. Lei n. 12.305, de 02 de agosto de 2010. Institui a Política Nacional de Resíduos Sólidos; altera a Lei n. 9.605, de 12 de fevereiro de 1998; e dá outras providências. Brasília- DF, ago 2010. 
BRASIL. Ministério das cidades. Secretaria Nacional de Saneamento Ambiental. Sistema Nacional de Informações sobre Saneamento (SNIS): diagnóstico do manejo de resíduos sólidos urbanos - 2014. Brasília- DF, 2016.

BRASIL. Ministério do Meio Ambiente. Conselho Nacional do Meio ambiente (CONAMA). Resolução n. 301, de 21 de março de 2003. Altera dispositivos da Resolução n. 258, de 26 de agosto de 1999, que dispõe sobre pneumáticos. BrasíliaDF, mar. 2003.

BRASIL. Ministério do Meio Ambiente. Conselho Nacional do Meio ambiente (CONAMA). Resolução n. 258, de 26 de agosto de 1999. Brasília- DF, ago. 1999.

BRASIL. Ministério do Meio Ambiente. Resolução CONAMA no 307, de 5 de julho de 2002. Estabelece diretrizes, critérios e procedimentos para a gestão dos resíduos da construção civil. Disponível em: < https://www.mma.gov.br/estruturas/a3p/_arquivos/36_09102008030504.pdf >. Acesso em: 12 de setembro de 2020.

FUNDAÇÃO NACIONAL DE SAÚDE (FUNASA). Ofício Circular n. 2/DIESP-TO, de 03 julho de 2018. Relatório de Vistoria de Aterros Sanitários. Palmas - TO, 2018.

GIL, A. C. Métodos e técnicas de pesquisa social. 5 ed. São Paulo: Atlas, 2006.

GURUPI. Prefeitura Municipal. Plano Municipal de Gestão Integrada de Resíduos Sólidos (PMGIRS). Gurupi-TO, ago. 2013.

INSTITUTO BRASILEIRO DE GEOGRAFIA E ESTATÍSTICA (IBGE). IBGE Cidades. Gurupi - TO. Disponível em: <https://cidades.ibge.gov.br/brasil/to/gurupi.> Acesso em: nov. 2018.

INSTITUTO BRASILEIRO DE GEOGRAFIA E ESTATÍSTICA (IBGE). Censo 2010IBGE. Disponível em: < https://censo2010.ibge.gov.br/> Acesso em: nov. 2018. 
MARTINS, F.L.R. Apenas três cidades do Tocantins possuem aterros sanitários. Jornal do Tocantins, 05 set. 2018. Disponível em: $<$ https://www.jornaldotocantins.com.br/editorias/estado/apenas-tr\%C3\%AAs-cidadesdo-tocantins-possuem-aterros-sanit\%C3\%A1rios-1.1610330>. Acesso em: nov. 2018.

MERSONI, Cristina; REICHERT, Geraldo Antônio. Comparação de cenários de tratamento de resíduos sólidos urbanos por meio da técnica da Avaliação do Ciclo de Vida: o caso do município de Garibaldi, RS. Disponível em:< https://www.scielo.br/pdf/esa/v22n5/1809-4457-esa-22-05-00863.pdf>. Acesso em 12 de Set. De 2020.

SECRETARIA L DE INFRAESTRUTURA. Prefeitura de Gurupi - TO. Gurupi - TO, 2018.

SECRETARIA DE PRODUÇÃO, COOPERATIVISMO E MEIO AMBIENTE. Prefeitura de Gurupi - TO. Gurupi - TO, 2018.

TOCANTINS. Lei Complementar № 93, de 3 de abril de 2014. Institui a Região Metropolitana de Gurupi, e adota outras providências. Palmas - TO, 2014.

Enviado: Setembro, 2020.

Aprovado: Outubro, 2020. 